\title{
Equações diferenciais no crescimento de fungos causadores de doenças de tronco em videira
}

\author{
Differential equations in the growth of fungi causing grapevine trunk diseases
}

\author{
Rafael Zanovelo Perin \\ Instituto Federal de Educação, Ciência e Tecnologia do Rio Grande do Sul (IFRS), \\ Campus Bento Gonçalves, Bento Gonçalves, RS, Brasil \\ http://orcid.org/0000-0002-7671-8372, rafael-perin@hotmail.com
}

Jamerson Fiorentin
Instituto Federal de Educação, Ciência e Tecnologia do Rio Grande do Sul (IFRS),
Campus Bento Gonçalves, Bento Gonçalves, RS, Brasil
http://orcid.org/0000-0001-8609-2177, jamerson.fiorentin01@gmail.com

Sandra Denise Stroschein Instituto Federal de Educação, Ciência e Tecnologia do Rio Grande do Sul (IFRS), Campus Bento Gonçalves, Bento Gonçalves, RS, Brasil http://orcid.org/0000-0003-3292-2491, sandra.stroschein@bento.ifrs.edu.br

\begin{abstract}
Marcus André Kurtz Almança
Instituto Federal de Educação, Ciência e Tecnologia do Rio Grande do Sul (IFRS), Campus Bento Gonçalves, Bento Gonçalves, RS, Brasil http://orcid.org/0000-0002-3895-4390, marcus.almança@bento.ifrs.edu.br
\end{abstract}

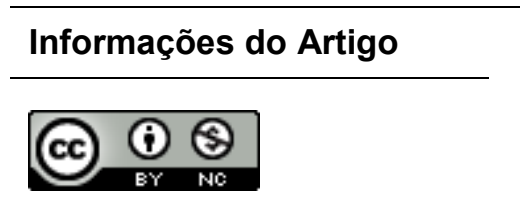

Histórico do Artigo

Submissão: 28 de março de 2019

Aceite: 07 de junho de 2019

Palavras-chave

Fitopatologia

Modelagem Matemática

Scilab Software

Experimento Laboratorial

\section{Resumo}

O presente trabalho versa sobre a modelagem da cinética de crescimento fúngico a partir de Equações Diferenciais Ordinárias, a fim de compará-la com o evento experimental. $O$ crescimento de uma população em meio limitado pode ser descrito pelo Modelo de Verhulst, proveniente da função logística. O experimento, realizado no Laboratório de Fitopatologia/IFRSBG, caracteriza-se no acompanhamento de 6 isolados fúngicos, sendo 3 da espécie Botryosphaeria dothidea e 3 da espécie Neofusiccocum parvum, causadores de doenças de tronco de videira. A partir dos dados experimentais, foi utilizado o software Scilab para o processamento das informações e exibição de gráficos. A rotina computacional aproximou os dados experimentais pelo Método de Mínimos Quadrados a uma equação quadrática, calculando a taxa de crescimento do fungo para o modelo. $O$ ajuste pelo método propiciou a modelagem do evento, por meio de Verhulst, obtendo a previsão do comportamento do crescimento de cada isolado. A partir disso, foi possível a comparação entre os dados experimentais com o modelado. Desse modo, concluiu-se que, com o modelo adotado, foi possível descrever a cinética de crescimento fúngico, entretanto ela não está relacionada com a espécie do fungo. Considerando todas as variações, foi constatado que as duas menores taxas de crescimento e maiores resíduos foram observados nos isolados TD 100 (N. parvum) e TD 316 (B. dothidea).

\section{Keywords}

Phytopathology

Mathematical Modeling

Software Scilab

Laboratory Experiment

\section{Abstract}

The present work is about the modeling of kinetics of fungal growth from Ordinary Differential Equations, in order to compare it with the experimental event. The growth of a population in a limited environment can be described by the Verhulst Model, derived from the logistic function. The experiment was carried out at the Laboratório de Fitopatologia/IFRSBG with 6 fungal isolates, 3 of the Botryosphaeria dothidea and 3 of the 
Neofusiccocum parvum, causing of the grapevine trunk diseases. From the experimental data, Scilab software was used for information processing and graphic display. The computational routine approximated the experimental data by the Least Squares Method to a quadratic equation, calculating the fungus growth rate for the model. The adjustment by the method allowed to model the event using Verhulst, with prediction of the growth behavior of each isolate. From this, it was possible to compare the experimental data with modeling. Thereby, it was concluded that, with the model adopted, it was possible to describe the kinetics of fungal growth, although it is not related to the fungus species. Considering all the variations, it was verified that the two lowest growth rates and the largest residuals was observed in the TD 100 (N. parvum) and TD 316 (B. dothidea) isolates.

\section{Introdução}

O desempenho da produção vitivinícola interfere diretamente na vida dos seus produtores, bem como na organização de regiões onde a cultura da videira é referência econômica, fazendo com que as perdas na tal produção sejam de interesse comum. Desse modo a viticultura é uma constante temática para pesquisa, visto que os avanços na área podem aprimorar a produção e evitar prejuízos (ALMANÇA et al., 2015).

As doenças da videira caracterizam-se assim como inimigos do sucesso econômico nas regiões produtoras, mediante aos danos que causam nas plantações, como a ocorrência de fungos. Com isso, antes da proposição ao combate às doenças faz-se necessário conhecer o seu desenvolvimento, e de acordo com Úrbez-Torres et al. (2006) um dos seus aspectos importantes a ser analisado é a característica de crescimento.

O acontecimento de um evento é singular, uma vez que as condições às quais ele está exposto influenciam a sua ocorrência. Ao controlarmos ou desconsiderarmos alguns fatores tornase possível descrever o seu acontecimento com maior facilidade e semelhança, por meio da Matemática.

Desse modo, a fim de estimar o evento de crescimento de um fungo podemos fazê-lo por meio de um modelo matemático, que "é uma forma de abstração e generalização com a finalidade de previsão de tendências", segundo Bassanezi (p. 24, 2009). Ou seja, é possível estimarmos a ocorrência do mesmo por meio de uma sentença matemática. Para isso utiliza-se da coleta e análise de dados, em conjunto com manipulações algébricas e simulações computacionais, com o objetivo de haver a maior semelhança entre os aspectos teóricos com as características do fenômeno.

\section{Referencial teórico}

A Modelagem Matemática possibilita a caracterização do crescimento fúngico na forma de uma equação diferencial, visto que se caracteriza em "uma equação em que as incógnitas são funções e a equação envolve derivadas destas funções" (SANTOS, 2011, p. 1). Com isso, o 
modelo proveniente de uma equação diferencial consegue estimar dados futuros e sistematizar o comportamento relativo à variação entre grandezas.

Dentre os diversos modelos já existentes tem-se a Dinâmica Populacional, a qual permite descrevermos a variação na quantidade dos indivíduos de uma determinada população $(P)$ de forma constante (ZILL; CULLEN, 2001). Assim, o crescimento populacional é dado pela variação da população inicial $\left(P_{O}\right)$ em determinado tempo $(t)$, ou seja, a taxa de variação da população é proporcional ao produto da população existente pela taxa de crescimento $(r)$, conforme a equação a seguir, também conhecida como Modelo de Malthus.

$$
\frac{d P}{d t}=r P
$$

A resolução desta equação pode ser feita por meio do Método de Separação de Variáveis, resultando na sua solução geral,

$$
P(t)=C e^{r t},
$$

em que $C$ é constante e $r$ a taxa de crescimento.

Se utilizado o Problema de Valor Inicial $(\mathrm{PVI})$ referente à população no tempo inicial, ou seja, $P(0)=P_{o}$. Assim, temos que $C$ é igual a $P_{o}$.

Logo, a solução da equação de Malthus é

$$
P(t)=P_{o} e^{r t}
$$

O surgimento de condições especiais no crescimento da população requer uma adaptação na equação dada, adequando-a ao evento. Tal fator acontece, conforme Zill (2011), visto que "casos reais de crescimento exponencial por um longo período são difíceis de encontrar, pois os recursos limitados do meio ambiente vão em algum momento restringir o crescimento da população" (p. 98). Então, espera-se que outros modelos possam descrever o crescimento populacional, mediante as variações.

Desse modo há a variação do modelo exponencial de Malthus para o Modelo de Verhulst, considerando a variação da população em dado tempo, mas em ambiente com capacidade de sustentação (SODRÉ, 2003). Ou seja, a população cresce até um limite máximo imposto pelo meio, o qual denominamos de capacidade de suporte $(k)$. Este novo modelo é dado pela equação

$$
\frac{d P}{d t}=P\left(r-\frac{r}{k} P\right)
$$

ou ainda,

$$
\frac{d P}{d t}-\operatorname{Pr}=-\frac{\mathrm{r}}{\mathrm{k}} P^{2}
$$


A equação correspondente a Verhulst caracteriza-se como não linear, sendo esta equação caracterizada como Equação de Bernoulli (SODRÉ, 2003). Os métodos de resolução podem ser por Separação de Variáveis, além do método de Bernoulli, devido as suas características. Se optarmos pelo primeiro é necessário utilizar frações parciais para a integração da equação, enquanto o outro irá demandar uma mudança de variável. E assim, obtém-se a solução geral

$$
P(t)=\frac{k}{1+C k e^{-r t}}
$$

Se utilizarmos as mesmas condições anteriores para o PVI, $P(0)=P_{o}$, em conjunto com manipulações algébricas, resultamos no próprio Modelo de Verhulst

$$
P(t)=\frac{P_{o} k}{P_{o}+\left(k-P_{o}\right) e^{-r t}}
$$

Dessa forma, podemos caracterizar então o crescimento fúngico, conforme Úrbez-Torres et al. (2006).

\section{Experimento}

Sendo o Laboratório de Fitopatologia, do Instituto Federal de educação, Ciência e Tecnologia do Rio Grande do Sul, Campus Bento Gonçalves (IFRS-BG), um espaço para o estudo das doenças causadas em plantas, desenvolvemos um experimento com fungos motivado pela disciplina de Equações Diferenciais, do curso de licenciatura em Matemática da mesma instituição.

A atividade em conjunto originou-se pela demanda da disciplina, conforme apresentado em Perin et. al.(2018), estendendo-se a necessidade do laboratório em conhecer e estimar a cinética de crescimento de determinados fungos causadores de doenças de tronco de videiras.

Fazendo uso dos espaços e materiais do laboratório, objetivando garantir a probidade do experimento, foram repicados 3 isolados, com 5 repetições, de cada um dos fungos: Botryosphaeria dothidea (B. dothidea) e Neofusiccocum parvum (N. parvum). Cada isolado corresponde a uma variação do fungo, sendo nomeados por TD em conjunto com um número, conforme a identificação da Micoteca² do laboratório.

No experimento, ilustrado pela Figura 1, o micélio de cada isolado foi colocado, para cada repetição, no centro de uma placa de Petri. Na placa, com $8 \mathrm{~cm}$ de diâmetro e com meio de cultura BDA (batata, dextrose e ágar) para o crescimento fúngico, também foram feitas marcações em diagonal, facilitando assim as medições do diâmetro da colônia em ambas direções.

\footnotetext{
${ }^{1}$ Equação diferencial não linear mais importante, da forma $\frac{d y}{d t}+p(t) y=y^{n} g(t)$, com $\mathrm{n}>1$.

2 Espaço para o condicionamento das amostras dos fungos.
} 
Figura 1 - llustração do experimento.

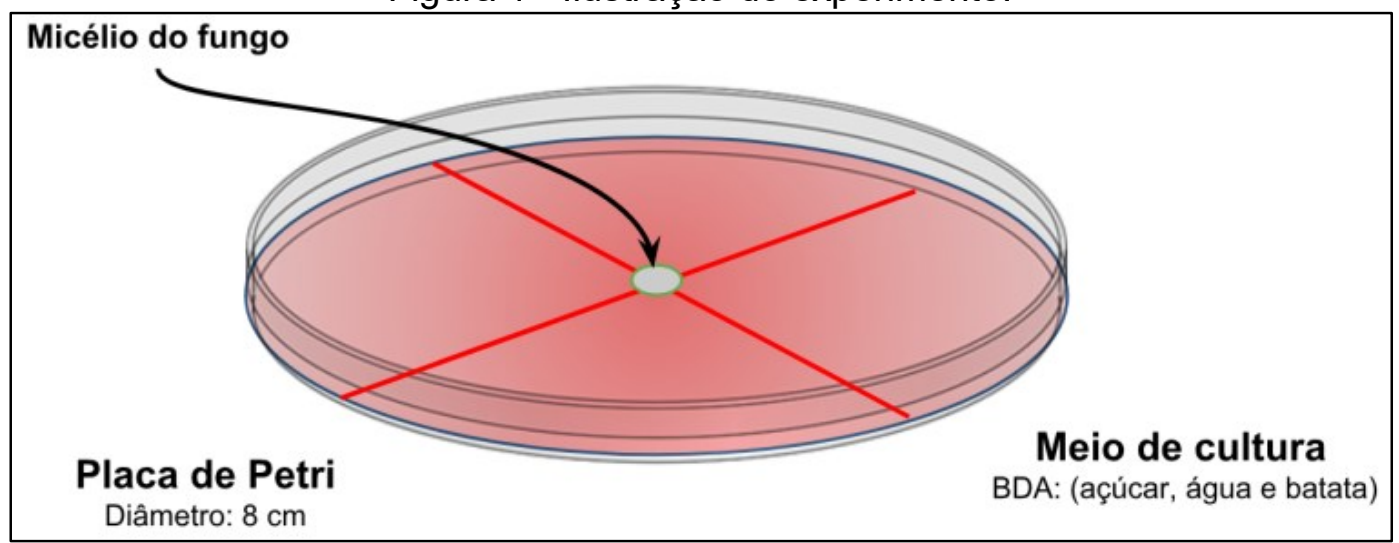

Fonte: Elaboração dos autores.

As 30 placas foram mantidas em câmara de crescimento com temperatura de $26{ }^{\circ} \mathrm{C}$ (oscilando em $1{ }^{\circ} \mathrm{C}$ para mais e para menos), com fotoperíodo de 12 horas, para o acompanhamento do crescimento da colônia fúngica. As medições foram feitas durante dez dias, a cada 12 horas.

Uma análise inicial qualitativa do comportamento das soluções é feita por meio do campo de direções, exibido na Figura 2. Com essa ferramenta observou-se que as soluções convergem para a solução de equilibro do sistema, enquanto o tempo aumenta. Ou seja, o crescimento da colônia apresenta a tendência em estabilizar-se na capacidade de suporte do meio, no caso $8 \mathrm{~cm}$, variando o tempo nesse ponto máximo conforme a taxa de crescimento.

Figura 2 - Representação gráfica do campo de direções.

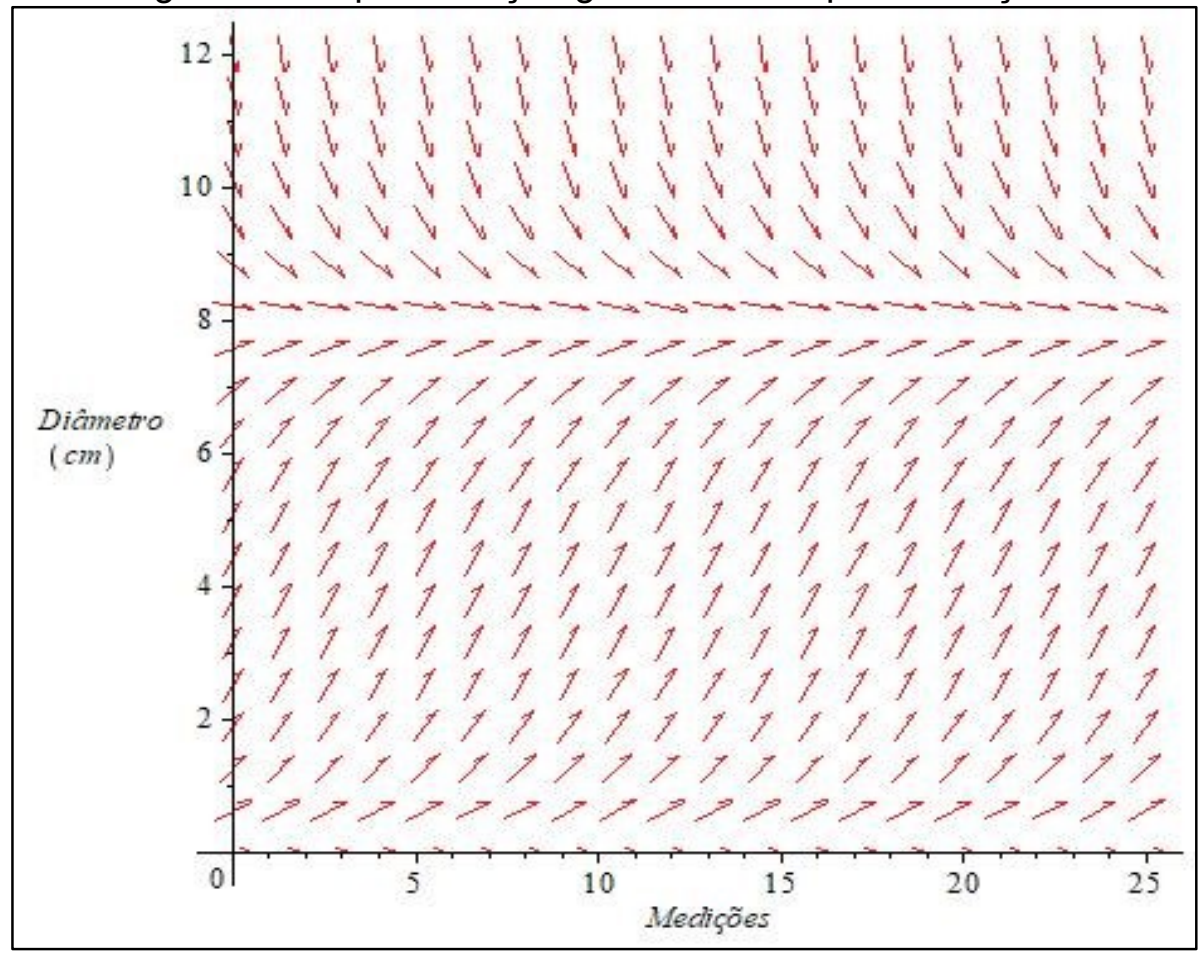

Fonte: Elaboração do autores. 
$\mathrm{Na}$ sequência da análise qualitativa pelo campo de direções desenvolveu-se o experimento, a fim de verificar tal ocorrência de forma experimental, como representado nas Figuras 3 e 4.

Figura 3 - Crescimento do fungo $B$. dothidea em meio de cultura BDA, 2 dias após a repicagem.

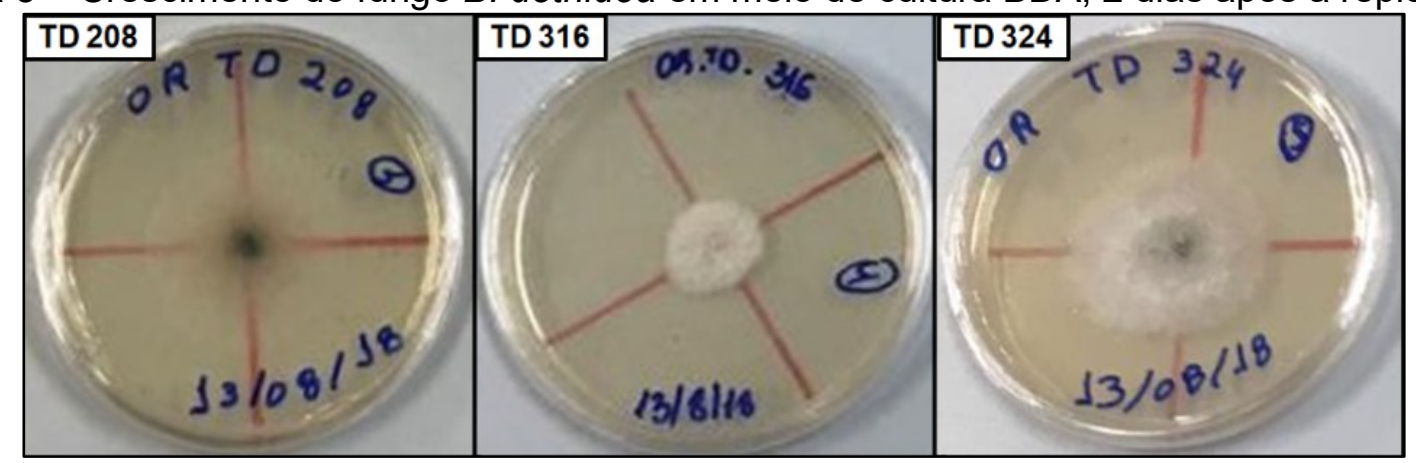

Fonte: Elaboração do autores.

Figura 4 - Crescimento do fungo N. parvum, em meio de cultura BDA, 2 dias após a repicagem.

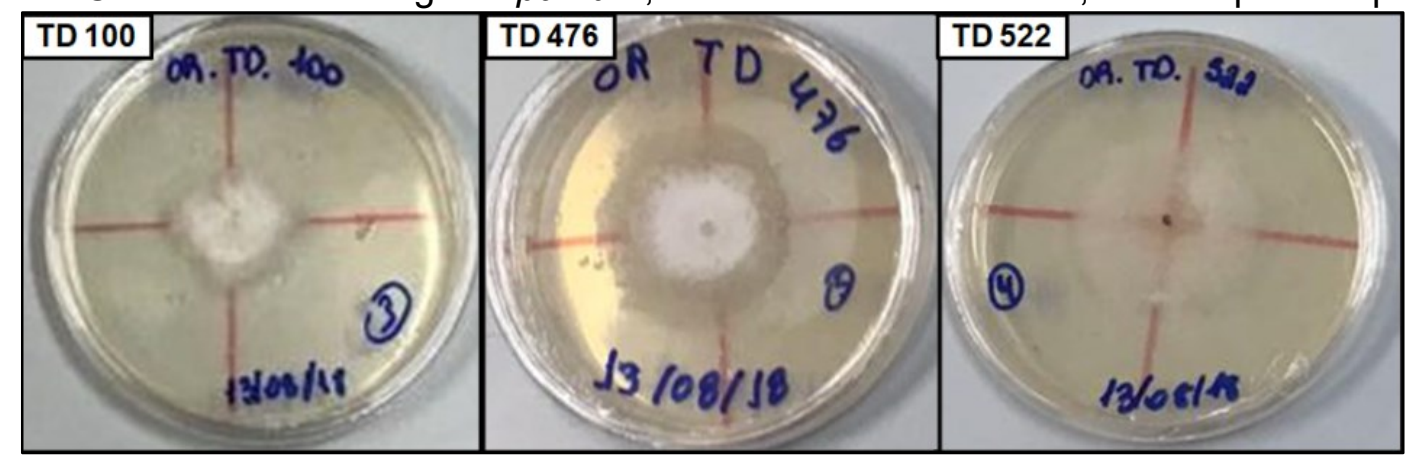

Fonte: Elaboração do autores.

Os dados foram obtidos por meio da média dos diâmetros, nas duas direções das diagonais, em cada intervalo de tempo. Na sequência foi realizada a média dos diâmetros de cada isolado, a fim de manter a integridade do experimento e considerar possíveis aspectos característicos. Ou seja, obtemos um diâmetro médio para o isolado no determinado tempo de medida, em centímetros.

Nos gráficos a seguir, representados nas Figuras 5 a 10, tem a média dos diâmetros das repetições de cada isolado sendo representada no eixo vertical, ou das ordenadas. Enquanto as medições constam no eixo horizontal, ou das abscissas, sendo que as médias da manhã correspondentes aos números pares e da noite pelos ímpares. 
Figura 5 - Representação gráfica do crescimento do isolado TD 208 do fungo $B$. dothidea.

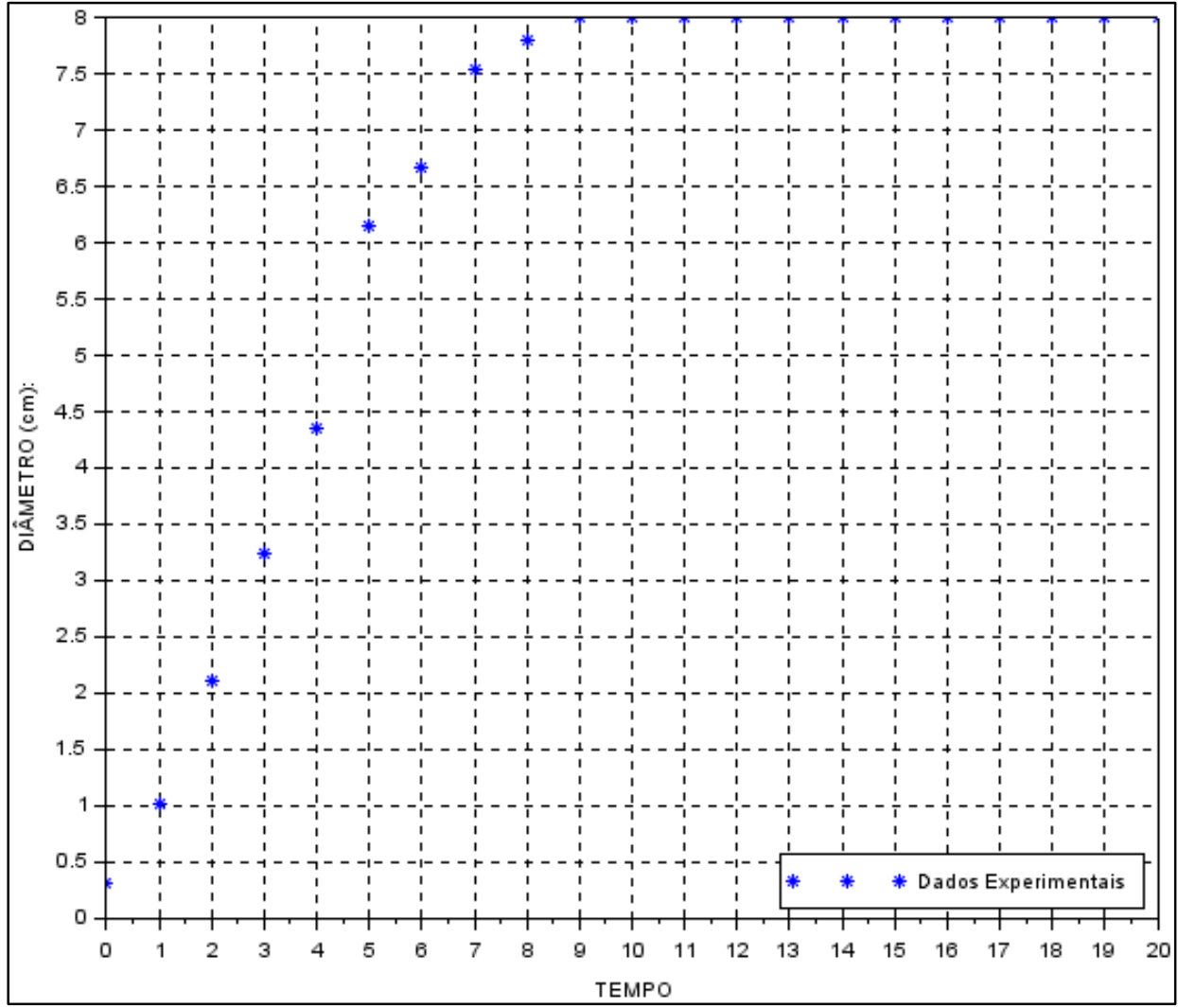

Fonte: Elaboração do autores.

Figura 6 - Representação gráfica do crescimento do isolado TD 316 do fungo $B$. dothidea.

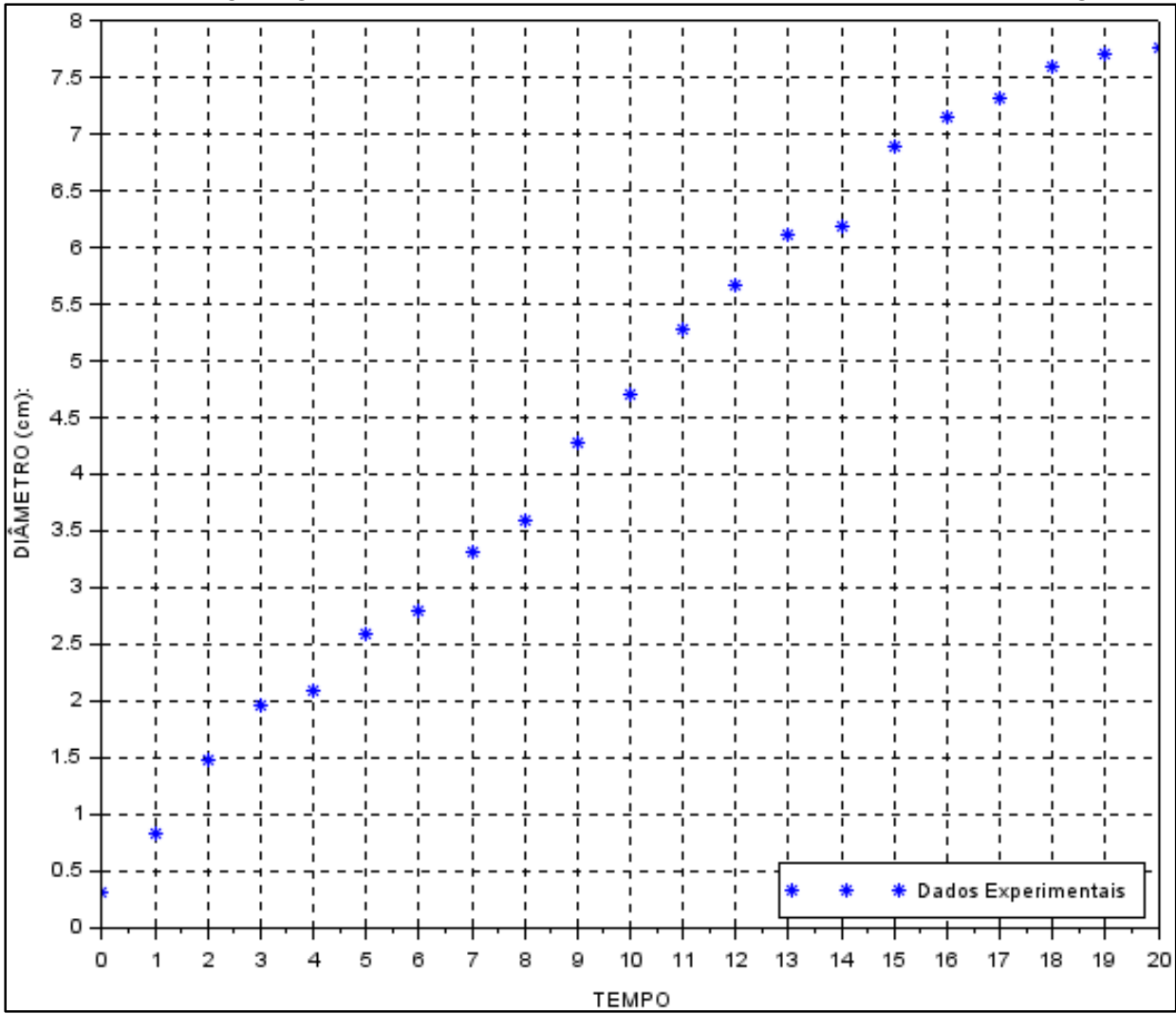

Fonte: Elaboração do autores. 
Figura 7 - Representação gráfica do crescimento do isolado TD 324 do fungo $B$. dothidea.

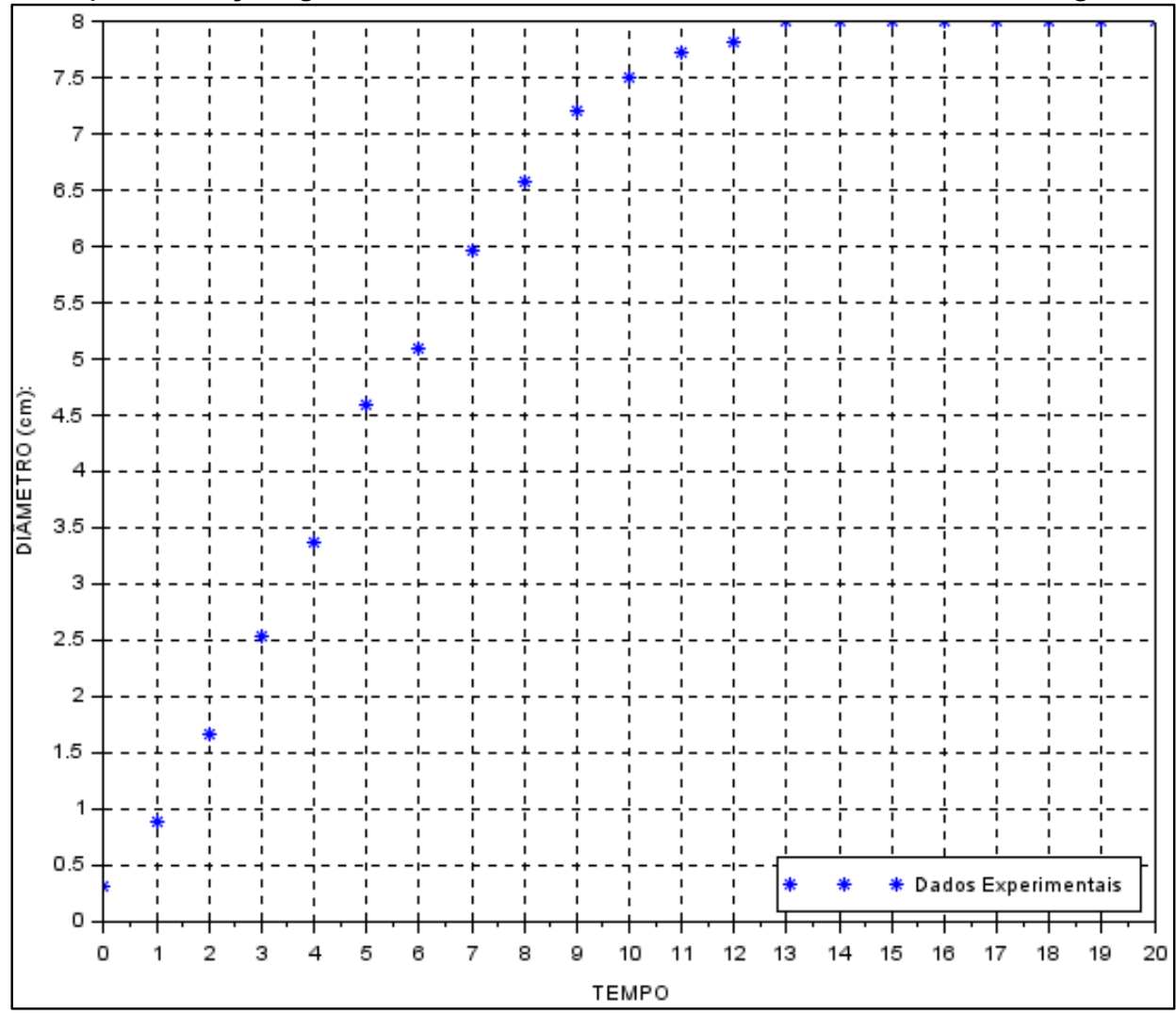

Fonte: Elaboração do autores.

Figura 8 - Representação gráfica do crescimento do isolado TD 100 do fungo N. parvum.

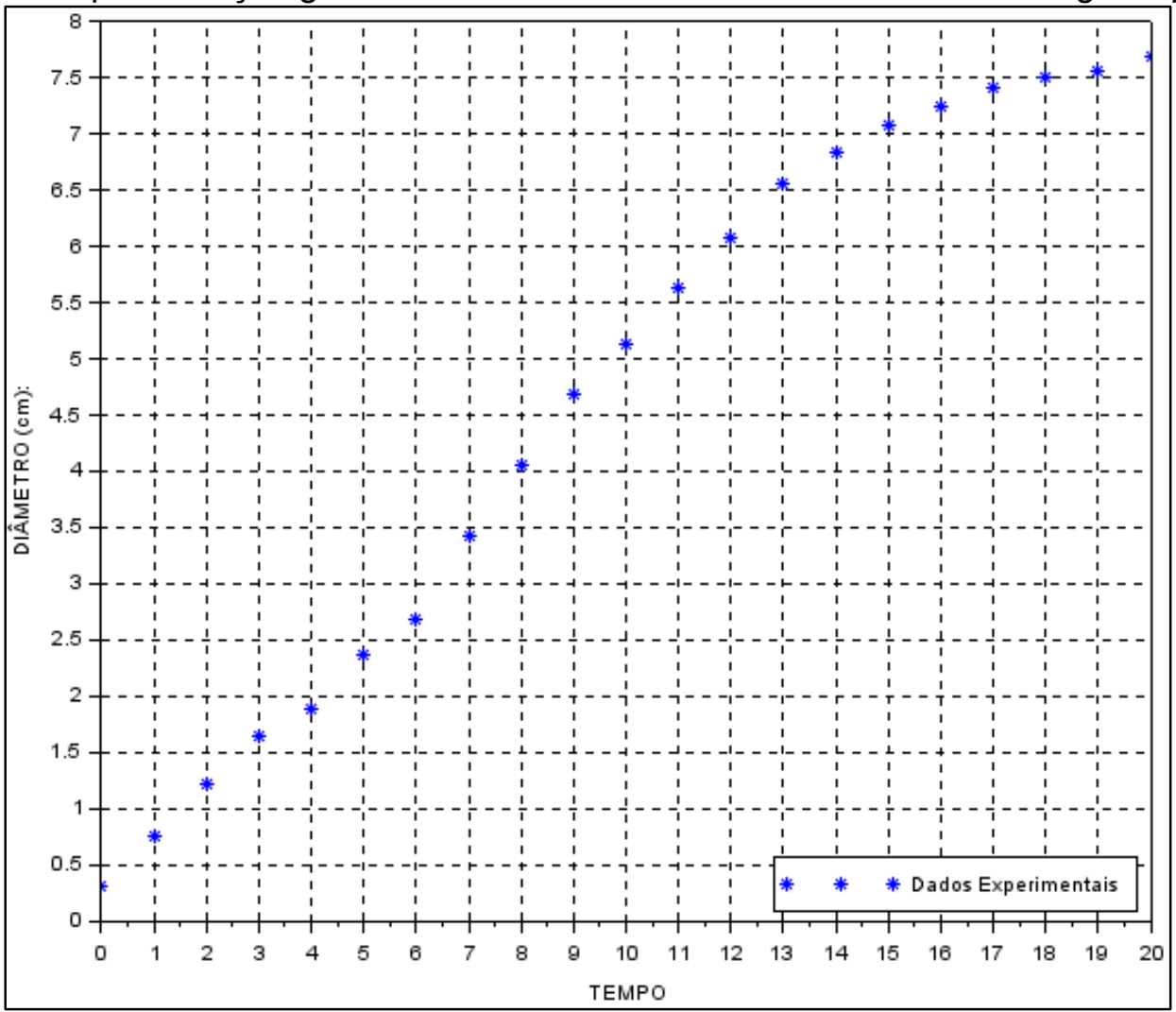

Fonte: Elaboração do autores. 
Figura 9 - Representação gráfica do crescimento do isolado TD 476 do fungo N. parvum.

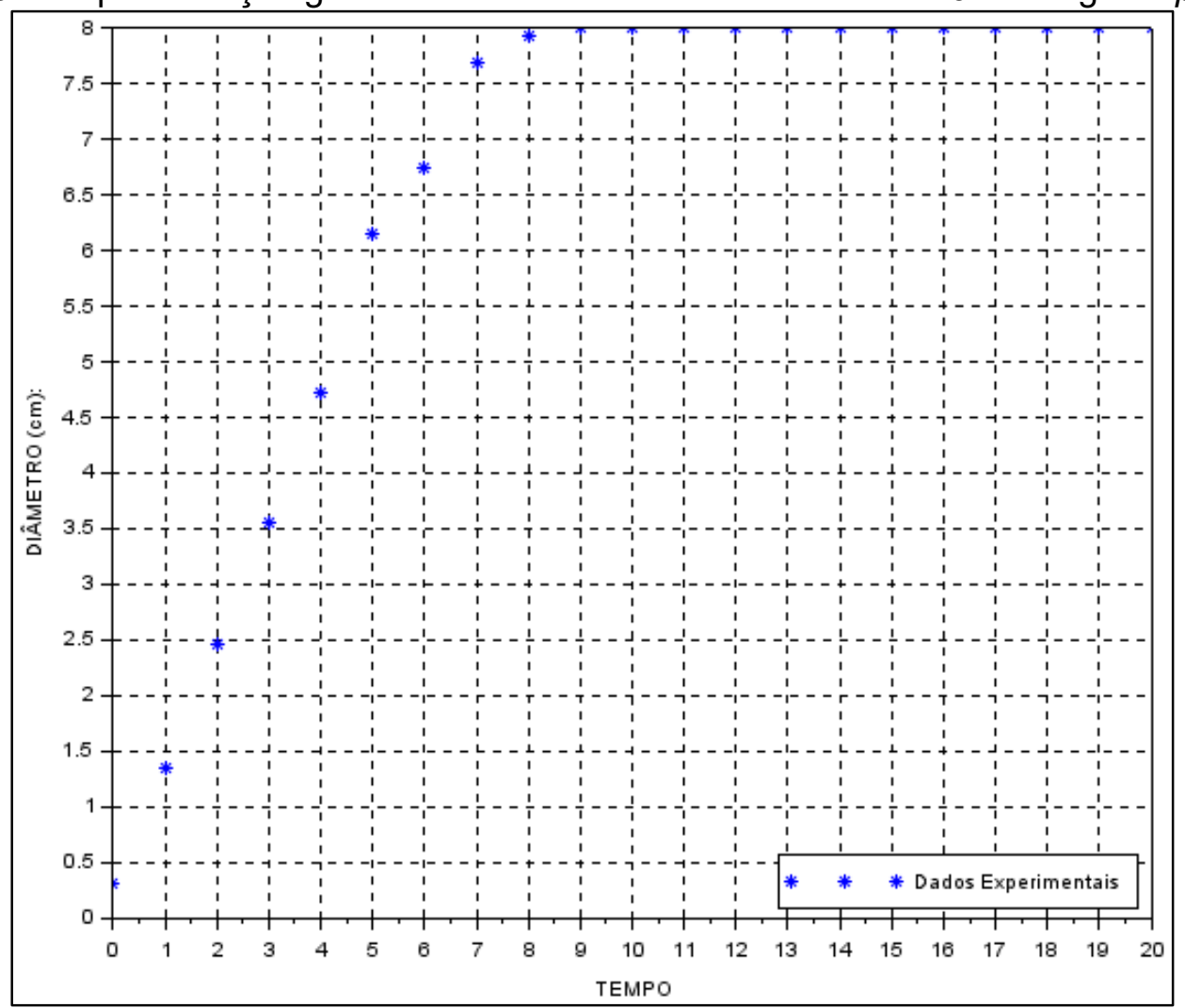

Fonte: Elaboração do autores.

Figura 10 - Representação gráfica do crescimento do isolado TD 522 do fungo N. parvum.

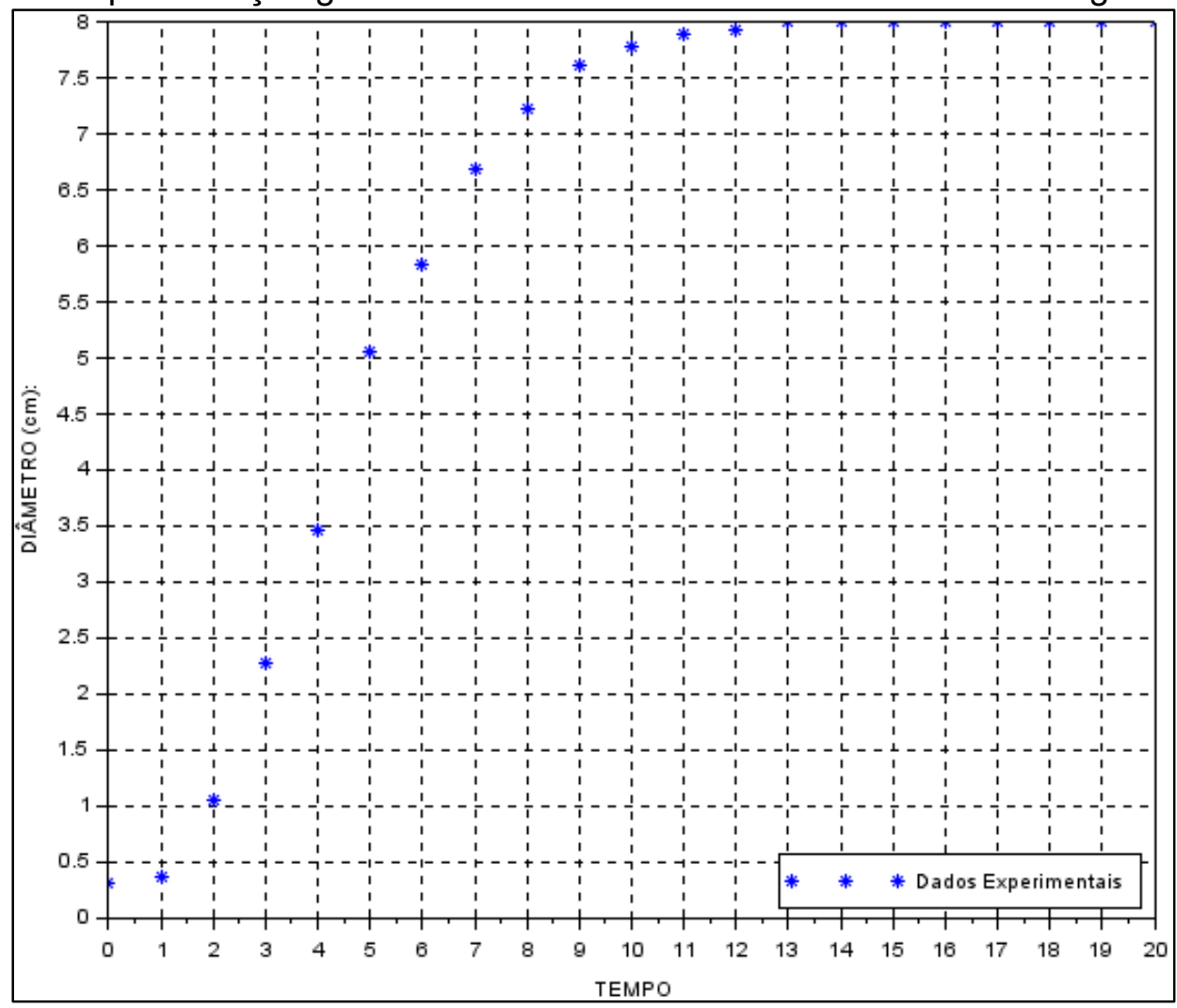

Fonte: Elaboração do autores. 
Os gráficos anteriores possibilitam observarmos como se dá o crescimento fúngico, tendo comportamento inicial de forma exponencial e a partir de dado ponto, o ponto de inflexão, o crescimento tende a capacidade de suporte do meio.

\section{Metodologia}

A representação gráfica dos dados, Figuras 5 a 10, em conjunto com as características do evento experimental confirmou a aplicação do Modelo de Verhulst, onde o crescimento da colônia de fungos é limitado pelo tamanho da placa. Dessa forma a equação permite a descrição do evento, mas é preciso modelar o fenômeno para estimarmos o crescimento do fungo.

No experimento já são conhecidos os dados presentes na equação de Verhulst, exceto a taxa de crescimento do fungo. Devido à ausência desse fator é necessário calculá-la, para após resolvermos a equação diferencial e obtermos a modelagem, possibilitando a comparação com o real. Os referidos passos devem ser seguidos para todos os isolados, tornando-se repetitivo.

Com isso, consideram-se as potencialidades e contribuições das ferramentas computacionais, as quais possuem desempenho mais assertivo e podem ser programadas para seguir determinada sequência de passos, um algoritmo. Desse modo, põe-se em destaque o software Scilab, o qual atende as necessidades citadas sem precisar de licença, ou seja, é livre (CAMPOS FILHO, 2010).

No presente trabalho a rotina computacional age de forma interativa, onde o usuário precisa informar as medidas e características experimentais, e então o programa retorna ao usuário as informações calculadas, como na Figura 11, sendo eles a curva de ajuste, a taxa de crescimento e o resíduo ${ }^{3}$ sendo nomeado de erro.

Figura 11 - Ambiente de interação da rotina computacional.

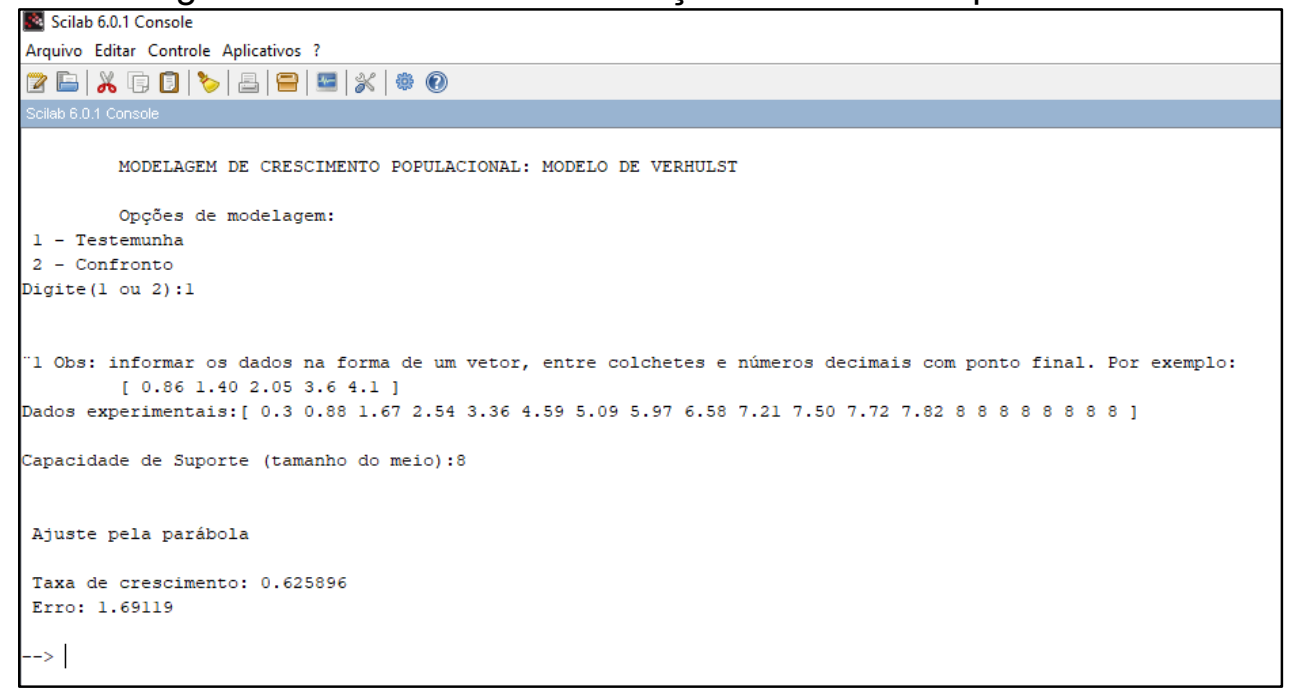

Fonte: Elaboração do autores.

\footnotetext{
${ }^{3}$ Conforme Watkins (2002), o resíduo é a medida de quão bem se ajustam as equações, ou seja, a diferença entre o experimental com o modelado.
} 
Na rotina computacional organizada no Scinotes, ambiente de programação do Scilab, os dados experimentais são aproximados a uma equação por meio do Método de Mínimos Quadrados, visto que:

Existem diversas maneiras de medir o quão "próxima" está a reta dos dados. A escolha usual (devido, a basicamente, à maior simplicidade dos cálculos) é somar os quadrados dos resíduos. A reta de mínimos quadráticos é a reta [...] que minimiza a soma dos quadrados dos resíduos. (LAY, 1999, p. 381).

Neste caso, citado acima, as informações são aproximadas a uma reta pelo Método de Mínimos Quadrados, encontrando a equação linear que melhor contempla tais valores. Entretanto, o evento abordado neste trabalho adequa-se melhor a uma curva, de acordo com Sodré (2003) e Farias et al. (2018), visto que é uma equação não linear.

O algoritmo realiza o ajuste utilizando o método citado por uma curva, aproximando os dados a uma parábola. Isso se deve ao fato do crescimento ser inicialmente exponencial e a partir do ponto de inflexão apresentar mudança de comportamento, fazendo com que na totalidade o evento seja melhor descrito a uma função quadrática. A partir da função quadrática encontrada pode-se calcular a taxa de crescimento do fungo, por meio da taxa de variação, e em decorrência disso o resíduo.

\section{Resultados}

A utilização do algoritmo desenvolvido sistematiza a modelagem de crescimento fúngico, permitindo-nos a execução rápida da estrutura mediante a alteração dos dados. Assim, utilizamos dos dados experimentais para realizar a Modelagem Matemática.

Os dados obtidos pelo evento laboratorial foram inseridos no programa, como descrito anteriormente. Desse modo obtivemos as informações desejadas, apresentadas na Tabela 1, seguindo as estruturas e programação do software.

Tabela 1 - Resultados de taxa de crescimento fúngico $(\mathrm{mm} / \mathrm{h})$ e resíduo, conforme os isolados utilizados.

\begin{tabular}{cccc}
\hline Fungo & Isolado (TD) & Taxa de crescimento $(\mathbf{m m} / \mathbf{h})$ & Resíduo \\
\hline \multirow{3}{*}{ Botryosphaeria dothidea } & 208 & 0,71582 & 2,74151 \\
& 316 & 0,44335 & 4,02856 \\
Neofusiccocum parvum & 324 & 0,69506 & 1,62648 \\
& 100 & 0,50648 & 4,45259 \\
& 476 & 0,69369 & 3,69018 \\
& 522 & 0,75843 & 0,75391 \\
\hline
\end{tabular}

Fonte: Dados da pesquisa.

Os isolados TD 522 e TD 208 apresentaram as maiores taxas de crescimento, enquanto TD 316 e TD 100 as mais baixas. A informação referente ao resíduo é calculada pela diferença 
entre os dados experimentais e do modelo, ou seja, quanto menor o resíduo mais próxima é a modelagem dos dados laboratoriais. Assim, o modelo dos isolados TD 324 e TD 522 são os que mais se aproximam da ocorrência do fenômeno, diferentemente do TD 316 e TD 100, os quais são os mais distantes.

Ao analisarmos os dados e compararmos o crescimento, tem-se que a característica de crescimento não é apresentada como uma condição da espécie do fungo, pois não há predomínio ou uniformidade entre os isolados. Tal afirmação pode ser vista ao compararmos o crescimento de dois isolados de mesmo fungo em mesma medição, Figuras 12 e 13.

Figura 12 - Comparativo de crescimento dos isolados TD 316 e TD 324, do fungo B. dothidea.

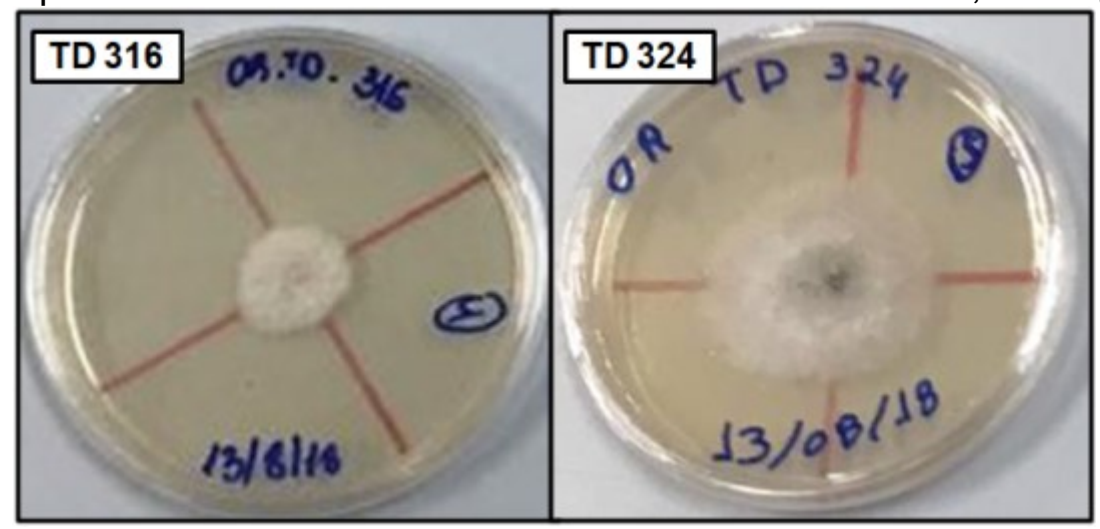

Fonte: Elaboração dos autores.

Figura 13 - Comparativo do crescimento dos isolados TD 100 e TD 522, do fungo N. parvum.

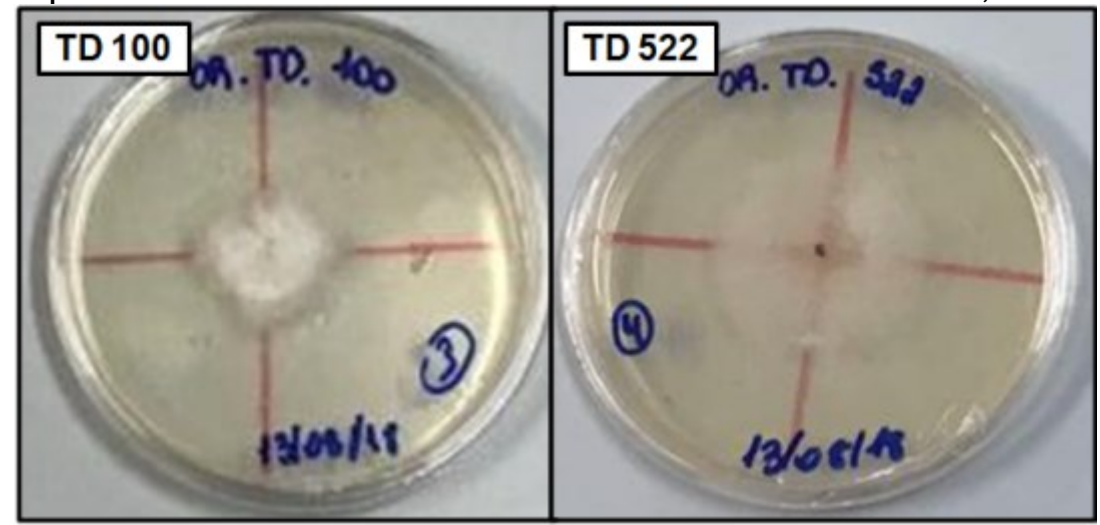

Fonte: Elaboração dos autores.

Além disso, destaca-se que os isolados com as menores taxas de crescimento são aqueles cuja divergência com o Modelo de Verhulst é mais expressiva, ou seja, o maior resíduo. Para isso, o algoritmo realiza a representação gráfica das informações, tanto experimental quanto modelada, no mesmo espaço de exibição, viabilizando a comparação das mesmas.

Nos gráficos a seguir, Figuras 14 a 19, são exibidas as informações provenientes do desenvolvimento laboratorial em vermelho, enquanto a curva em azul é referente a modelagem. 
Figura 14 - Representação gráfica da modelagem de crescimento fúngico do isolado TD 208 do fungo B. dothidea.

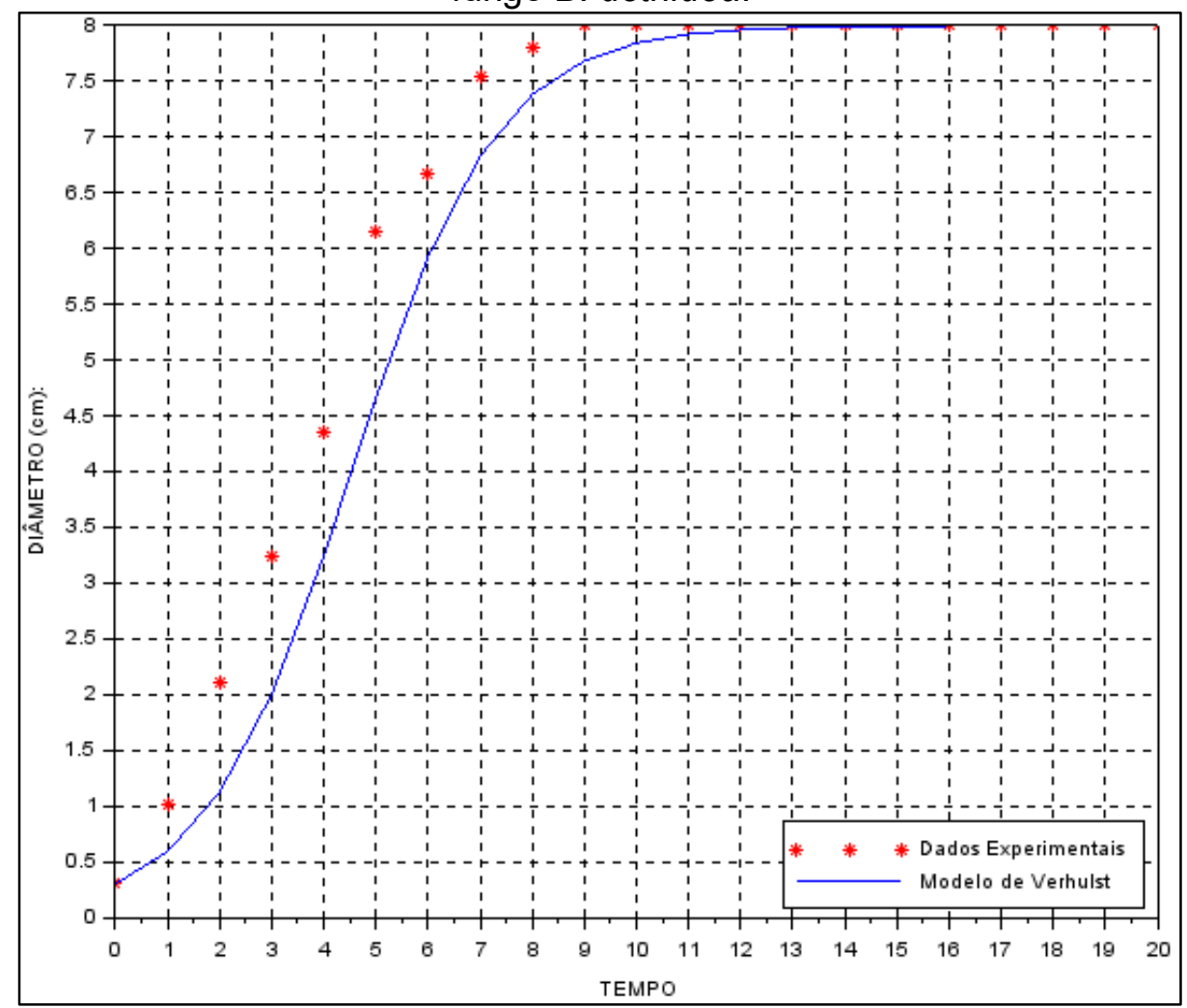

Fonte: Elaboração dos autores.

Figura 15 - Representação gráfica da modelagem de crescimento fúngico do isolado TD 316 do fungo $B$. dothidea.

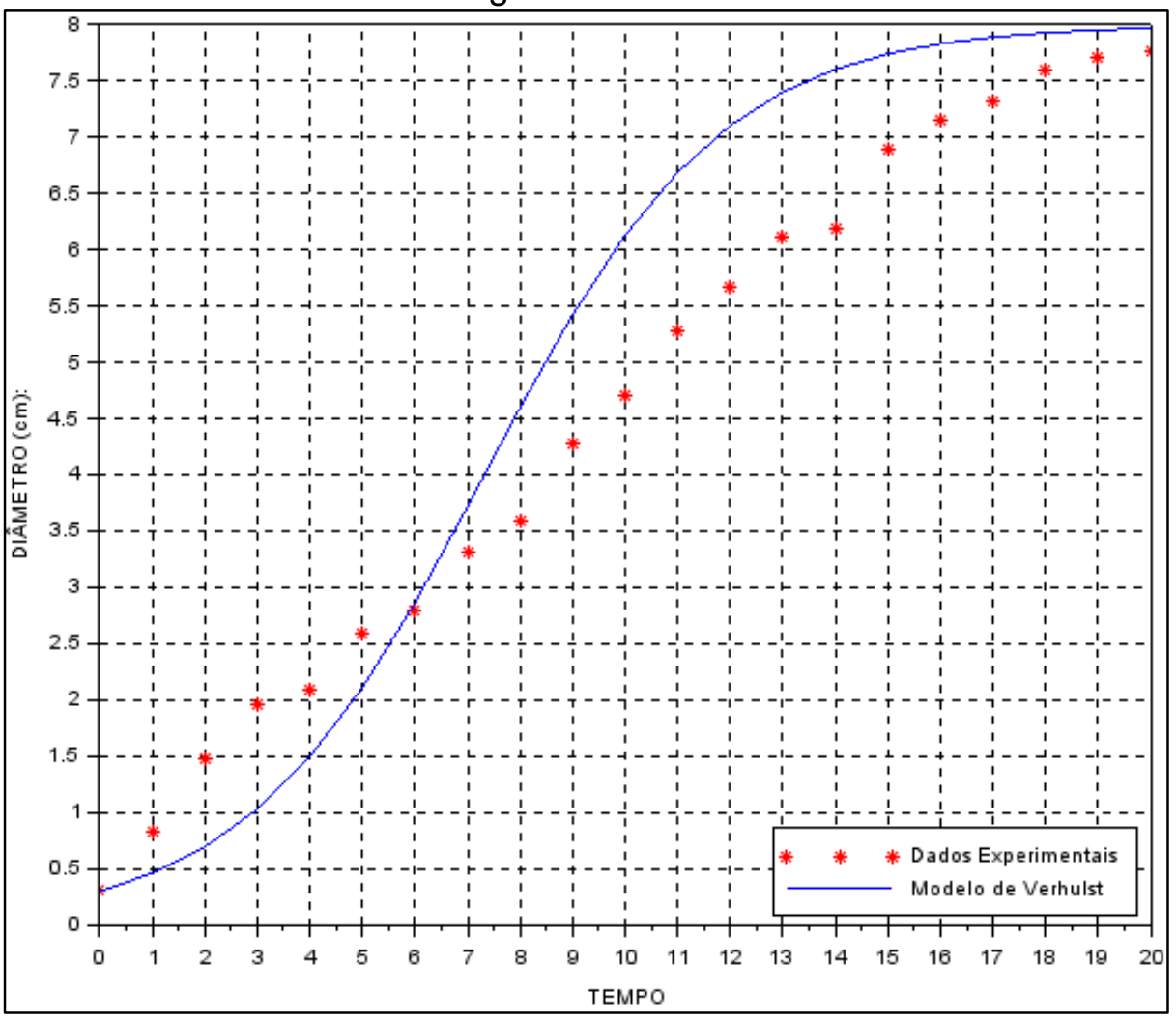

Fonte: Elaboração dos autores. 
Figura 16 - Representação gráfica da modelagem de crescimento fúngico do isolado TD 324 do fungo $B$. dothidea.

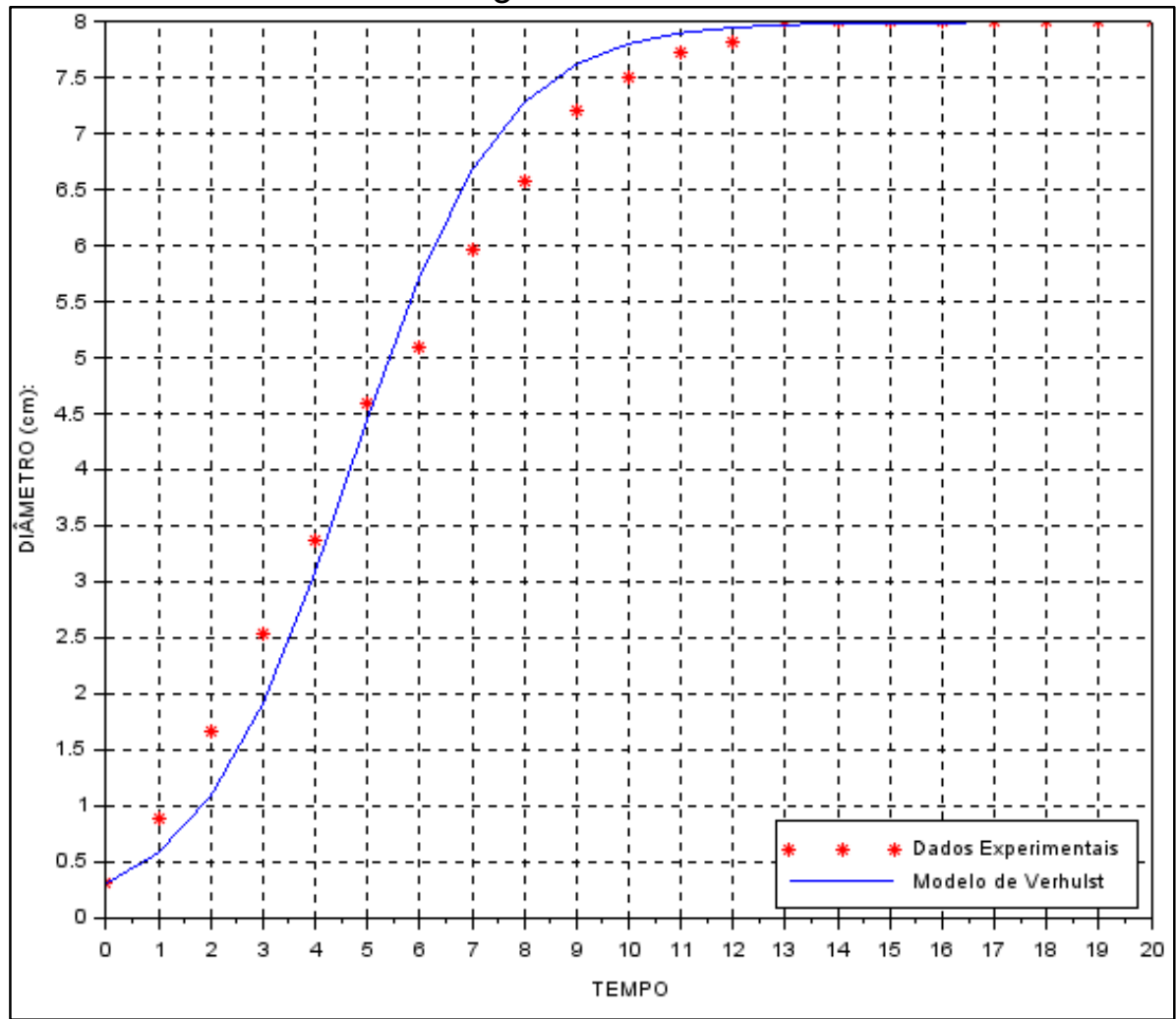

Fonte: Elaboração dos autores.

Figura 17 - Representação gráfica da modelagem de crescimento fúngico do isolado TD 100 do fungo N. parvum.

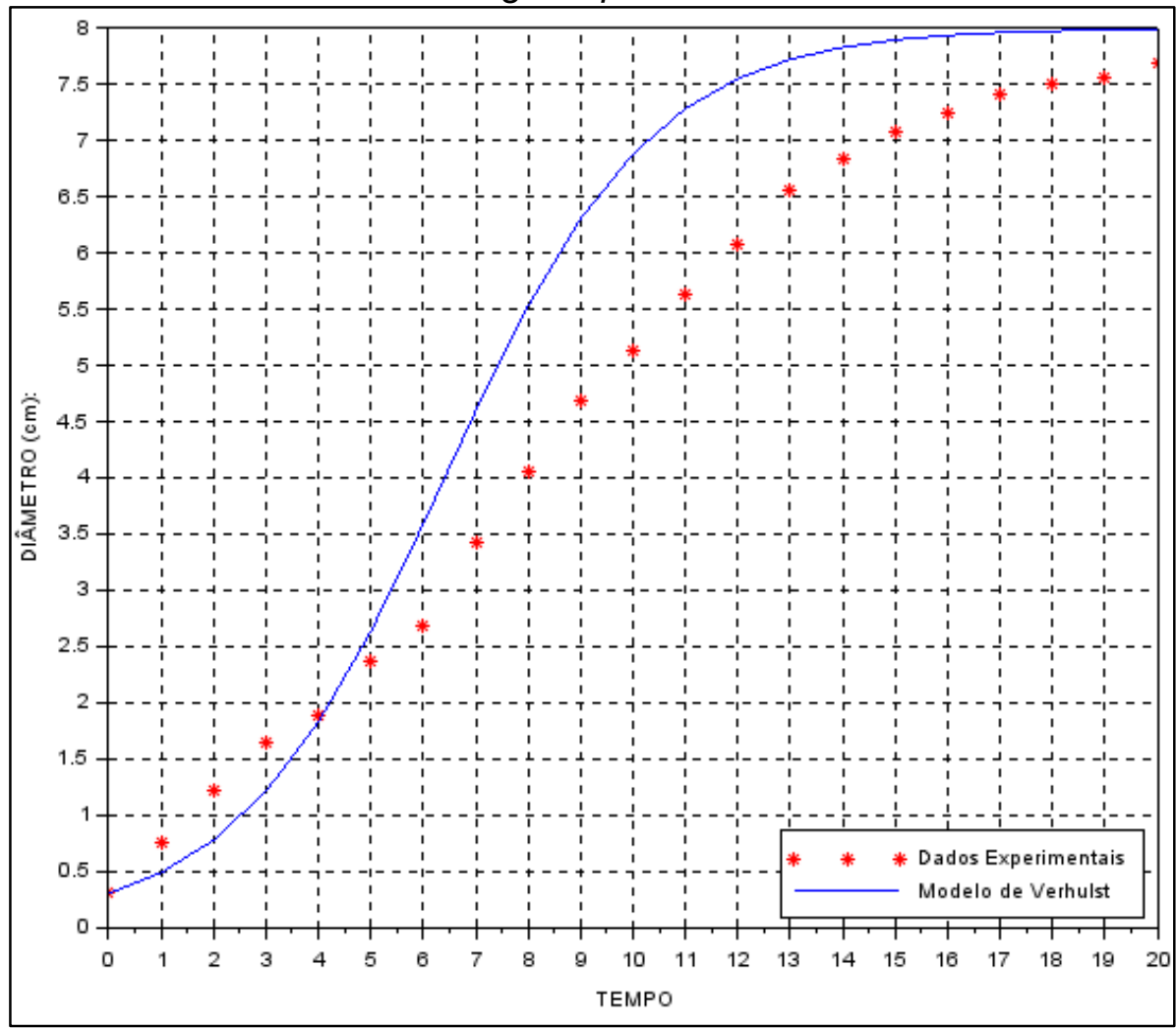

Fonte: Elaboração dos autores. 
Figura 18 - Representação gráfica da modelagem de crescimento fúngico do isolado TD 476 do fungo N. parvum.

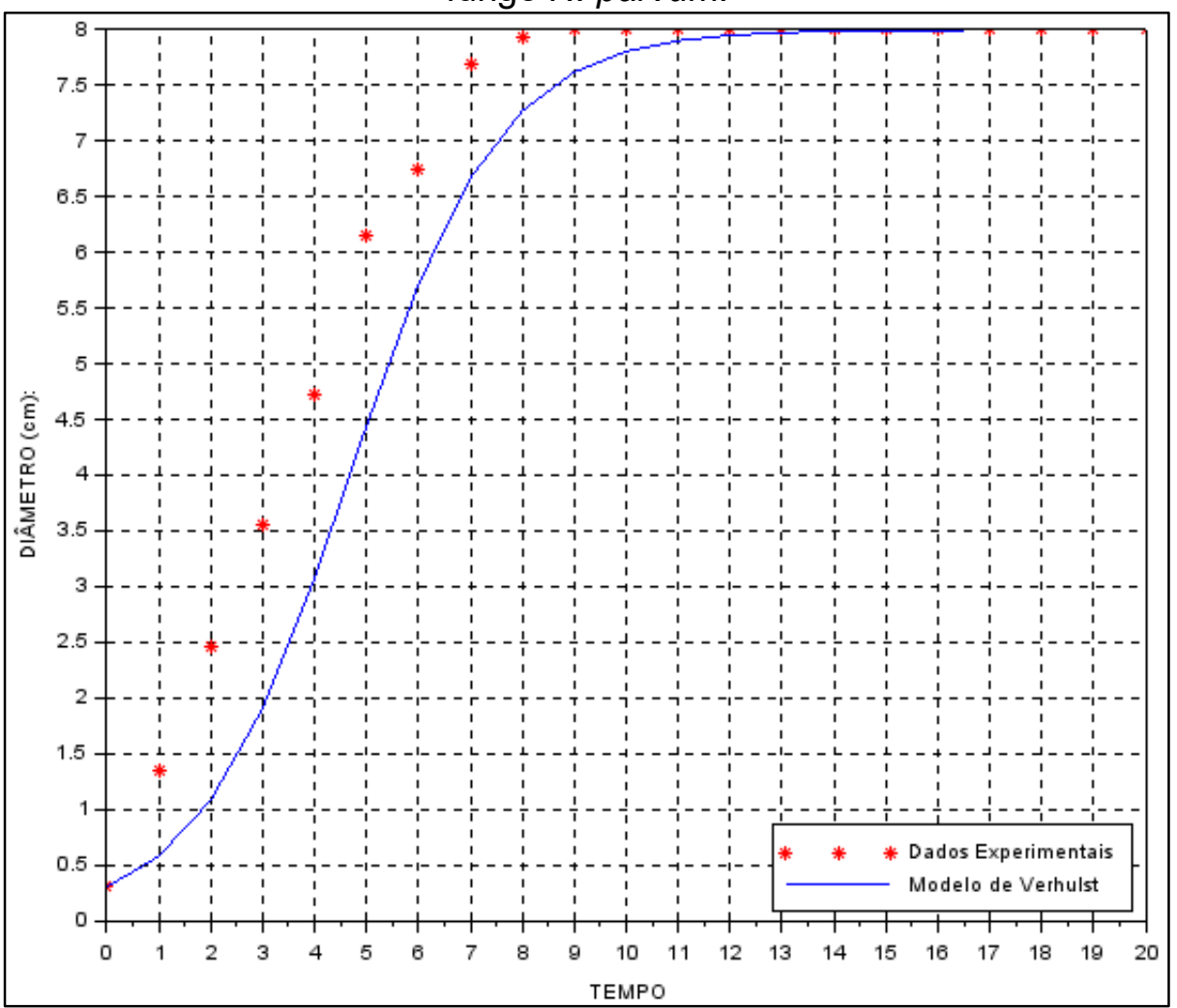

Fonte: Elaboração dos autores.

Figura 19 - Representação gráfica da modelagem de crescimento fúngico do isolado TD 522 do fungo N. parvum.

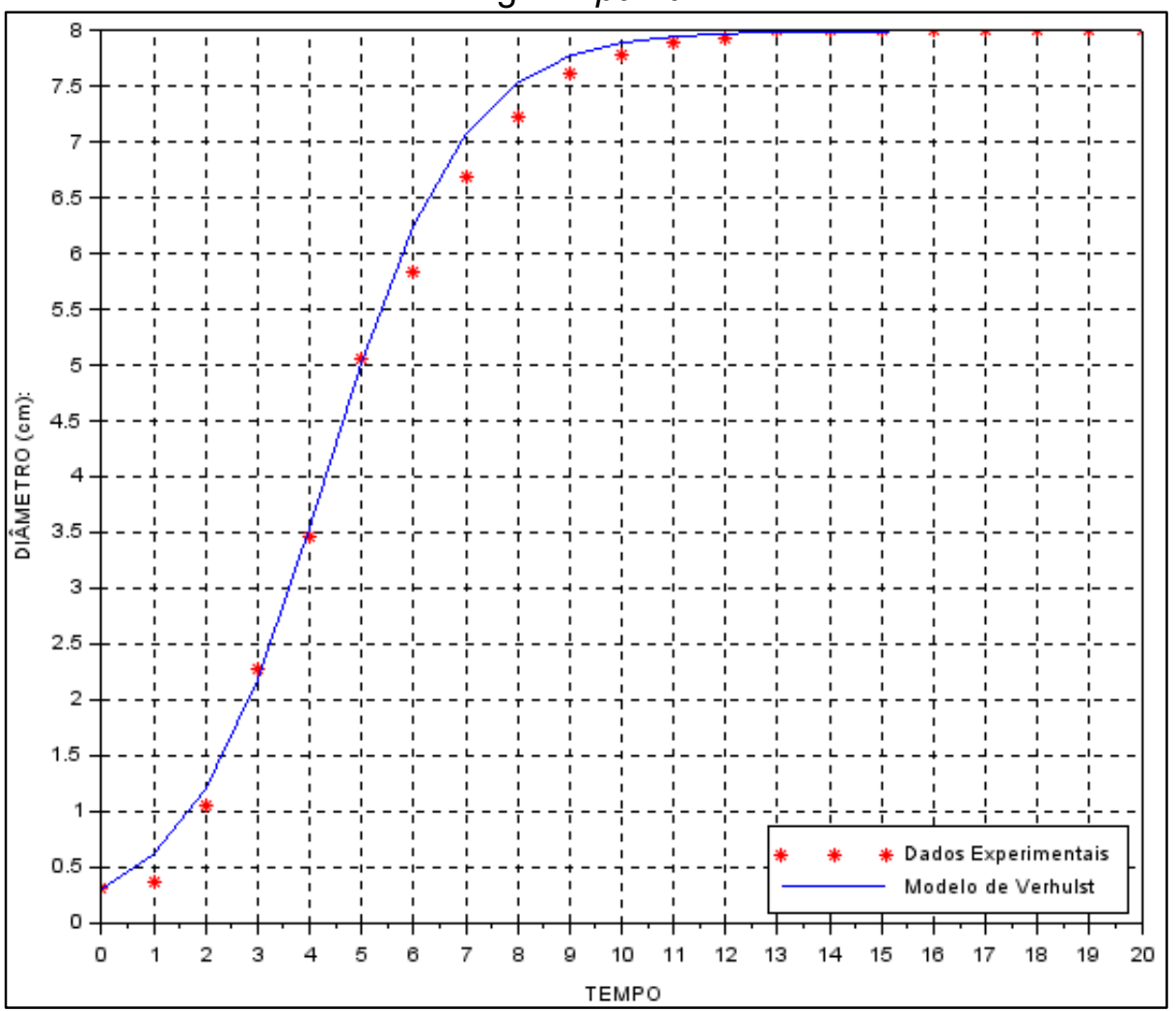

Fonte: Elaboração dos autores. 
Os gráficos exibem as informações processadas computacionalmente, permitindo a análise dos dados numéricos com as características gráficas. Por exemplo, como no gráfico do TD 522, Figura 19, a curva do modelo se aproxima dos dados experimentais, ou seja, há uma pequena diferença entre eles, sendo esse o menor resíduo.

Ainda, ao observarmos as Figuras 14 a 19, é visível a conformidade com a análise qualitativa, apresentada na Figura 2. O comportamento em ambas destaca o crescimento exponencial no início do evento, e após certo ponto o crescimento apresenta a tendência em estabelecer-se na capacidade de suporte.

\section{Considerações finais}

As pesquisas em Matemática Aplicada oportunizam contribuições entre áreas adversas, propiciando aspectos e resultados até então desconsiderados. Muitas vezes tais estudos deixam de ser realizados pela falta de conhecimento nas Ciências Exatas, sendo desse pressuposto oriunda a parceria entre a Matemática e a Fitopatologia no IFRS-BG.

A partir deste trabalho em questão atendeu-se a uma demanda do laboratório de Fitopatologia, a qual diz respeito à realização de cálculos e a organização dos mesmos de forma gráfica. Mediante ao bom resultado em tal parceria, o algoritmo desenvolvido para a pesquisa foi adaptado para implementação no laboratório, passando a ser mais autoexplicativo e autossuficiente, não demandando de conhecimentos matemáticos ou de programação na utilização do mesmo. Desse modo, pesquisas em Ciências Agrárias até então deixadas de lado poderão ser contempladas, contribuindo assim com a produção vitivinícola da região bem como aspectos científicos.

O retorno positivo na proposta se dá em consonância com o desenvolvimento de conhecimentos interdisciplinares e o aprimoramento nas próprias ciências exatas. Dada a relevância citada, é importante realizarmos melhorias nas atividades, sejam elas referentes aos procedimentos laboratoriais de medição, aspectos computacionais e teóricos de Matemática. Dentre os pontos citados, julgamos necessário rever o algoritmo, visando melhorar o condicionamento a fim de minimizar o resíduo da modelagem.

Por fim, temos que o Modelo de Verhulst descreve sim o crescimento logístico de uma colônia de fungos, possibilitando ser estimado por meio da modelagem. E, no caso dos fungos Botryosphaeria dothidea e Neofusiccocum parvum a característica de crescimento não é uma condição da espécie, uma vez que há variação dentre seus isolados. Entretanto, ao surgimento de futuras pesquisas na área será necessário rever os métodos utilizados, em caso de modificações nas condições de crescimento. 


\section{Referências}

ALMANÇA, M. A. K; LERIN, S.; CAVALCANTI, F. R. Doenças da videira. Informe Agropecuário, Belo Horizonte, v. 36, n. 289, p. 7-12, 2015.

BASSANEZI, R. C. Ensino-aprendizagem com modelagem matemática. 3. ed. São Paulo: Contexto, 2009.

CAMPOS FILHO, F. F. Fundamentos de Scilab. Belo Horizonte: Departamento de Ciências da Computação do ICEx, 2010. Disponível em:

<https://www.ime.unicamp.br/ encpos/VIII EnCPos/Apostila Scilab.pdf>. Acesso em: 03 jan. 2019.

FARIAS, D. M; KONZEN, P. H. de A; SOUZA, R. R. (Orgs.). Álgebra Linear: Um livro colaborativo. 2018. Recursos Educacionais Abertos de Matemática. Disponível em: <https://www.ufrgs.br/reamat/AlgebraLinear/livro/livro.pdf>. Acesso em: 03 jan. 2019.

LAY, D. C. Álgebra Linear e suas Aplicações. Trad.: CAMELIER, Ricardo; IÓRIO, Valéria de Magalhães. 2. ed. Rio de Janeiro: Livros Técnicos e Científicos, 1999.

PERIN, Rafael Zanovelo; MUTTIN, Chiara; FIORENTIN, Jamerson; ALMANÇA, Marcus Kurtz; STROSCHEIN, Sandra Denise. Equações diferenciais para a modelagem de crescimento fúngico. In: MOSTRA TÉCNICO-CIENTÍFICA, Bento Gonçalves, 2018. Anais da Mostra TécnicoCientífica, IFRS, Bento Gonçalves, RS, v. 1, out. 2018. Disponível em: <https://eventos.ifrs.edu.br/index.php/secbg/mtc2018/paper/viewFile/6123/2226>. Acesso em: 25 maio 2019.

SANTOS, R. J. Introdução às Equações Diferenciais Ordinárias. Belo Horizonte: Imprensa Universitária da UFMG, 2011. Disponível em: < http://arquivoescolar.org/bitstream/arquivoe/107/1/iedo.pdf>. Acesso em: 03 jan. 2019.

SODRÉ, U. Equações Diferenciais Ordinárias. Notas de aula: Computação, Engenharia Elétrica e Engenharia Civil. Londrina, 2003. Disponível em:

<http://www.uel.br/projetos/matessencial/superior/pdfs/edo.pdf>. Acesso em: 03 jan. 2019.

ÚRBEZ-TORRES, J. R.; LEAVITT, G. M.; VOEGEL, T. M.; GUBLER, W. D. Identification and distribution of Botryosphaeria spp. associated with grapevine cankers in California. Plant Disease, v. 90, n. 12, p. 1490-1503, 2006.

WATKINS, D. S. Fundamentals of matrix computations. 2. ed. New York: John Wiley \& Sons, 2002.

ZILL, D. G; CULLEN, M. R. Equações Diferenciais. Prefácio de Ubiratan D'Ambrosio. Trad.: ZUMPANO, Antônio. 3. ed. São Paulo: Pearson, v. 1, 2001.

ZILL, D. G. Equações Diferenciais com aplicações em modelagem. Tradução da 9a edição Norte Americana. São Paulo: Cengace Learning, 2011. 410 p. 